\title{
Predicting Tobacco Smoking among Adolescents Using Social Capital and Media Exposure With Theory of Planned Behavior: Path Analysis Evidence From Indonesia
}

\author{
Sujono Riyadi ${ }^{1}$, Bhisma Murti ${ }^{2}$, Muhammad Akhyar $^{3} \&$ Suminah $^{4}$ \\ ${ }^{1}$ Doctoral Program of Health Promotion and Community Development, Universitas Sebelas Maret, Surakarta, \\ Indonesia \\ ${ }^{2}$ Masters Program in Public Health, Universitas Sebelas Maret, Surakarta, Indonesia \\ ${ }^{3}$ Faculty of Teaching and Educational Sciences, Universitas Sebelas Maret, Surakarta, Indonesia \\ ${ }^{4}$ Faculty of Agriculture, Universitas Sebelas Maret, Surakarta, Indonesia \\ Correspondence: Sujono, Doctoral Program of Health Promotion and Community Development, Universitas \\ Sebelas Maret, Jl. Ir. Sutami 36A, Surakarta 57126, Central Java, Indonesia. E-mail: \\ sujono_kmpk2005@yahoo.com
}

Received: April 10, 2019 Accepted: May 14, 2019 Online Published: May 30, 2019

doi:10.5539/gjhs.v11n7p18 URL: https://doi.org/10.5539/gjhs.v11n7p18

\begin{abstract}
Tobacco smoking remains an ongoing and dire public health threat globally. Identifying factors that influence individuals' smoking behavior is critical especially among adolescents. This study aimed to determine the effects of media exposure to tobacco advertisement, social capital, and other factors, on tobacco smoking among adolescents using Theory of Planned Behavior (TPB). This cross-sectional study was conducted in KulonProgo District, Yogyakarta Province, Indonesia, in April 2018. The dependent variable was smoking behavior. The independent variables were intention to smoke, attitude toward smoking, knowledge about tobacco use, subjective norm toward smoking, perceived behavior control not to smoke, media exposure to cigarette advertisement, and social capital among peer adolescents. The data were collected by questionnaire and analyzed by path analysis run on Stata 13 . The TPB constructs including attitude toward smoking $(\mathrm{b}=0.90 ; 95 \% \mathrm{CI}=$ 0.29 to $1.51 ; \mathrm{p}=0.004)$, subjective norm toward smoking $(\mathrm{b}=1.59 ; 95 \% \mathrm{CI}=0.99$ to $2.19 ; \mathrm{p}<0.001)$, and perceived behavior control not to smoke $(b=-2.07 ; 95 \% \mathrm{CI}=-2.68$ to $-1.45 ; \mathrm{p}<0.001)$, had impact on intention to smoke and smoking behavior. Exposure to tobacco advertisement had indirect impact on smoking behavior through attitude toward smoking and intention to smoke. Weak social capital had indirect impact on smoking behavior through subjective norm toward smoking and intention to smoke. It concludes thatTPB can be used to explain smoking behavior among adolescents.
\end{abstract}

Keywords: smoking, determinants, theory of planned behavior, social capital, adolescents

\section{Introduction}

Tobacco smoking remains an ongoing and dire public health threat globally, including Indonesia. Every year, more than 225,700 of Indonesian people are killed by tobacco-caused disease Deaths (\%) caused by tobacco in 2016 was $21.37 \%$ in men and 7.02\% in women in Indonesia. More than 53,248,000 adults (15+ years old) continue to use tobacco each day. Prevalence of tobacco smoking was $76.2 \%$ in men and $3.6 \%$ in women in Indonesia. Tobacco use among youth is even alarming and rapidly increasing. More than 469,000 children (10-14 years old) smoke daily. Prevalence of tobacco smoking was 3.51\% among boys $0.39 \%$ among girls aged $10-14$ years old (Tobacco Atlas, 2018). Tobacco use, both in smoke and smokeless mode, is a cause of concern among South Asian communities living in the Western World (Khaja et al., 2016). Another study from Colombia reported that smokers had a higher inclination to get involved in harmful alcohol consumption (Amaya, 2018).

Identifying factors that influence individuals' smoking behavior remains a huge public health concern. A study in Kuwait reported that several factors motivate students to smoke, including family members, friends and classmates who smoke (AlKandari, 2016). In an attempt to understand the psychosocial determinants of smoking initiation and maintenance, a variety of health behavior theories has been applied, including Theory of Planned Behavior 
(TPB) (Topa \& Moriano, 2010). For example, a study from China reported that the subjective norm, a TPB construct, was negatively associated with behavioral intention to cease smoking (Shimazaki et al., 2018). The TPB is an extension of the Theory of Reasoned Action (TRA). The theory states that attitude toward behavior, subjective norms, and perceived behavioral control (PBC), together shape an individual's behavioral intentions and ultimately behaviors. It incorporates personal factors as predictors of health behavior (LaMorte, 2018).

Social capital has lately received much attention in public health. Social capital has been defined as the resources to which individuals or groups have access through their social relationships (Moore \&Kawachi, 2017). Social capital has been suggested to have effects on health by at least four different causal mechanisms, including: (1) the norms and attitudes that affect health-related behaviors; (2) psychosocial mechanisms that both serve to psychologically enhance self-esteem, confidence and control, and that may have biological effects (for instance by activating the hypothalamic-pituitary-adrenocortical axis); (3) social networks, which tend to increase the access to healthcare as well as other amenities; and (4) by a lowering effect on crime rates (Lindstorm, 2008). For example, a group randomized, controlled trial in 26 Dutch schools that provided junior secondary education demonstrated that promotion of certain norms and peer pressure could prevent smoking among adolescents (Lundborg, 2005). Another study reported that active social participation (as a common social capital proxy) was positively associated with smoking cessation $(\mathrm{OR}=1.39 ; 95 \% \mathrm{CI}=1.07-1.82)$ (Lindstrom \& Giordano, 2016).

There has been considerable debate as to how social capital influences behaviors such as smoking. However, there are plausible hypotheses as to how social capital may affect cigarette smoking, which include: i) deterring socially 'deviant' behavior; ii) increased dissemination of positive health messages; iii) increased access to resources, i.e. greater availability and use of (smoking) prevention services, and; iv) providing a buffer against psychosocial stress (Lindstrom \& Giordano, 2016).

However, not all social capital is good capital. Social connections, which may lead to beneficial outcomes for some individuals or groups, may lead to detrimental outcomes for others (Moore et al., 2009). Social capital producing negative outcomes is generally called as negative social capital. The potential downsides include restrictions on individual freedom, excess claims on group members, putting a barrier in social mobility, and exclusion of outsiders. For example, a study reported that among persons with a high school degree or more, higher social capital was associated with a higher sense of mastery. However, among less-educated persons, higher individual social capital was associated with lower mastery (Moore et al., 2009). Mastery has been defined as the extent to which one sees one's life chances as being under one's own control, and is considered an important dimension of psychological well-being and distress (Ilany \& Akçay, 2016).

To the extent of the author's knowledge, there were no earlier studies which incorporated the role of social capital into the Theory of Planned Behavior (TPB) in the explanation as to how social capital affects tobacco smoking behavior. This study aimed to analyze the determinants of tobacco smoking among youth using Theory of Planned Behavior, social capital, path analysis model, and empirical data obtained from an Indonesian population.

\section{Method}

\subsection{Study Design}

This was a cross-sectional study conducted in Kulon Progo District, Yogyakarta Province, Indonesia. The data were collected in April 2018.

\subsection{Population and Sample}

Target population was adolescents aged 12-18 years old. The accessible population was adolescents aged 12-18 years old who went to junior and senior high schools. The sample was selected based on smoking status. As smoking status was the dependent variable under study, this sampling method is called as fixed disease sampling. The sample size of this study was 400 subjects, consisting of 200 subjects who smoked and 200 subjects who did not smoke. Since sample data were analyzed using path analysis model, in order to have confidence in the goodness of fit test, a sample size of 100 to 200 is recommended. In general a model should contain 10 to 20 times as many observations as variables. This study analyzed 8 variables, therefore a minimum sample size of 160 ( 8 variables $\mathrm{x} 20$ subjects) was required. Hence, the sample size of 400 subjects participating in this study exceeded the minimum required sample size (Wolf et al., 2013).

\subsection{Study Variables}

The dependent variable was smoking behavior. The independent variables were intention to smoke, attitude toward smoking, knowledge about tobacco use as it related to health, subjective norm toward smoking, perceived behavior control not to smoke, media exposure (e.g. exposure to cigarette advertisement), and social capital among peer 
adolescents. Study subjects responded to a 20 minute questionnaire of smoking behavior.

\subsubsection{Smoking Status}

Study subjects were classified as current smoker if the subjects were daily smokers or non-daily smokers (also known as occasional smokers), or classified as non-smokers if otherwise. Daily smoker refers to those who respond "every day" to the question "At the present time do you smoke cigarettes every day, occasionally or not at all?". Non-daily smoker often referred to as "occasional" smoker, refers to those who respond "Occasionally" to the question "At the present time do you smoke cigarettes every day, occasionally or not at all?"(Government of Canada, 2008).Frequency of smoking was measured by asking question "how many cigarettes do you smoke per day?".

\subsubsection{Intention Toward Cigarette Smoking}

It was defined as the participant's subjective probability (i.e. perceived likelihood) that he/she would engage in tobacco smoking behavior. Seven questions assessed smoking intentions. Participants were asked 7 questions using a 5 -point scale (from 1 to 5 where $1=$ strongly disagree and $5=$ strongly agree). For example, participants answered questions such as: "I intend to smoke within the next two weeks" (Strongly Agree/Strongly Disagree). The resulting continuous data were then reclassified into two categories coded 0 for weak $(<$ mean $)$ and 1 for strong ( $\geq$ mean) intention to smoke.

\subsubsection{Attitude toward Cigarette Smoking}

Attitude toward smoking was defined as a person's summary evaluation of smoking (the attitude object), which might be "positive" (good) or "negative" (bad) (Huong et al., 2016). Study participants reported their global evaluation toward smoking using a semantic differential measure of smoking such as "nice versus awful,"“"pleasant versus unpleasant," and "fun versus not fun" (Macy et al., 2012). The attitude construct was measured by 13 questions with a 5-points scale answer (from 1 to 5 where $1=$ strongly disagree and $5=$ strongly agree). The resulting continuous data were then reclassified into two categories coded 0 for positive $(<$ mean) and 1 for negative ( $\geq$ mean) attitude toward smoking.

\subsubsection{Knowledge on Smoking}

Knowledge was defined as a theoretical or practical understanding, familiarity, and awareness of smoking as related to health issues, including cigarette types, hazardous smoke exposure, and smoking-related diseases. This construct was measured by 21 questions with "true" or "false" answers. For data analysis, the resulting continuous data were transformed into two categories coded 0 for poor knowledge $(<$ mean) and 1 for good knowledge $(\geq$ mean).

\subsubsection{Subjective Norm}

Subjective or perceived norm of smoking was defined as the perceived social pressure to perform or not to perform smoking behavior (Shimazaki et al., 2018). It was an individual's perception or "opinion" about what important others believe the individual should perform or not perform smoking behavior in a specific situation (Hanson, 2018). This construct was measured by 9 questions such as "Smoking is considered acceptable by the society", "It is common for host to offer cigarettes for guests", or "Smoking is permitted at any place as long as it does not disturb others". For data analysis, the resulting continuous data were transformed into two categories coded 0 for acceptable $(<$ mean) and 1 for unacceptable $(\geq$ mean $)$.

\subsubsection{Perceived Behavior Control}

This variable was defined as the study subject's perception of the ease or difficulty of performing the behavior of interest, i.e. smoking behavior. This variable or construct was constructed by 10 questions with a 5-points scale answer including 1 = strongly disagree, $2=$ disagree, $3=$ doubtful, $4=$ agree, and $5=$ strongly agree. The typical questions include one such as: "It is difficult for me not to smoke", or "I refrain from smoking when my smoker friends are surrounding me". For data analysis, the resulting continuous data were transformed into two categories coded 0 for weak $(<$ mean) and 1 for strong $(\geq$ mean).

\subsubsection{Media Exposure}

Media exposure to tobacco advertisement was defined as exposure to commercials containing name, logo, product name, and trademark of a tobacco manufacturer, trader or distributor, displayed in television, radio, newspaper, magazine, billboard, pamphlet, or disseminated trough social media such as facebook, whatsapp, instagram. This variable was measured by 16 questions with a 5 -points scale answer including $1=$ never, $2=$ rarely, $3=$ sometimes, $4=$ often, and $5=$ always. For data analysis, the resulting continuous data were transformed into two categories 
coded 0 for low $(<$ mean $)$ and 1 for high $(\geq$ mean $)$.

\subsubsection{Social Capital}

Social capital in this youth smokers study was defined associal relations within peer group with the notion of trusts, norms of reciprocity, and informal networks that can be capitalized as valuable resources for its members. It was measured by 8 questions such as "I trust that the other member of the peer group will handle his freedom and make socially controllable", "I trust that members will bring about mutual benefits for the peer group", and "When I give a hand to other peer group members in need, they will do the same when I need help". The questions were constructed with a 5 -points scale answer (from 1 to 5 where $1=$ strongly disagree and $5=$ strongly agree). For data analysis, the resulting continuous data were transformed into two categories coded 0 for weak $(<$ mean) and 1 for strong ( $\geq$ mean) social capital.

\subsection{Data Analysis}

The current study employed path analysis for data analysis run using Stata 13 (StataCorp, 2018). Path analysis is the statistical technique that allows an examination of causal relationships between one or more independent variables, either continuous or categorical, and one or more dependent variables, either continuous or categorical. First developed by Sewall Wright in the 1930s, path analysis is a second generation multivariate method (the first generation being a multiple regression) based upon a linear equation system, which was still used recently to analyze smoking behavior among adolescent using Theory of Planned Behavior (Gaioso et al., 2015). Path analysis was employed in this data analysis since it allows an estimation of both direct and indirect relationships between variables. As such it enables data analysis using Theory of Planned Behavior framework in this study. The analyses of both direct and indirect relationship between variables were not possible if a multiple regression analysis model was used instead.

Path analysis proceeded in 5 steps: (1) Model specification; (2) Model identification; (3) Model fit; (4) Coefficient estimates; and (5) Model re-specification (if necessary).

Model specification is the exercise of formally stating a model. Model identification concerns whether a unique value for each parameter can be obtained from the observed data, which implies that the researcher should calculate degree of freedom (df). Degree of freedom is calculated by comparing the number of observed variables with the sum of the number of endogenous variables, the number of exogenous variables, and the number of parameter to be estimated. A path model is called as just identified if $\mathrm{df}=0$. It is called as over-identified if $\mathrm{df}>0$. It is called as under-identified if $\mathrm{df}<0$. Path models need to be over-identified or just identified in order to be estimated and to test hypotheses about relationships among variables (Ullman, 1996). Model fit is the exercise of comparing the suitability of the path model specified by the researcher with the saturated (i.e. ideal) model based on sample data according to the computer. The path model is re-specified if it does not fit with the saturated model. To adjust a model, new pathways are added or original ones are removed.

\subsection{Research Ethics}

Research ethics approval was granted by the Research Ethics Committee at Universitas Jenderal AchmadYani Yogyakarta, No. SKep/330/KEPK/IV/2018. Study participants were taken through the process of informed consent and they signed consent forms before enrollment into the study. The information given to the participants included objective, procedures, potential risks, and benefits of the study. Participants had the right to refuse participation at any time.

\section{Results}

\subsection{Sample Characteristics}

Table 1. Sample characteristics $(n=400)$

\begin{tabular}{|c|c|c|}
\hline Variable & Frequency (n) & Percent (\%) \\
\hline \multicolumn{3}{|l|}{ Gender } \\
\hline Male & 341 & 85.3 \\
\hline Female & 59 & 14.8 \\
\hline Total & 400 & 100 \\
\hline
\end{tabular}




\begin{tabular}{lcc}
\hline Adolescent's age & 300 & 75 \\
Early adolescent (12-16 years) & 100 & 25 \\
Late adolescent (17-18 year) & $\mathbf{4 0 0}$ & $\mathbf{1 0 0}$ \\
Total & & 51 \\
\hline Family income (rupiah) & 204 & 31.3 \\
$<$ Rp 1,500,000 & 125 & 9.5 \\
Rp 1,500,000 to Rp 2,500,000 & 38 & 8.3 \\
Rp 2,500,000 to Rp 3,500,000 & 33 & $\mathbf{1 0 0}$ \\
$>$ Rp 3,500,000 & $\mathbf{4 0 0}$ & 82 \\
Total & & 14.3 \\
\hline Pocket money & 328 & 3.8 \\
$<$ Rp 15,000 & 57 & $\mathbf{1 0 0}$ \\
Rp 15,000 to Rp 25,000 & 15 & Standard Deviation: 3.36 \\
$>$ Rp 25,000 & $\mathbf{4 0 0}$ & \\
Total & Mean: 3.31 & Median: 2 \\
\hline Number of cigarette smoked per day & & Max: 20 \\
\hline
\end{tabular}

\subsection{Bivariate Analysis}

Table 2. Sample characteristics by smoking status among youth $(\mathrm{n}=400)$

\begin{tabular}{|c|c|c|c|c|c|c|c|c|}
\hline \multirow{2}{*}{ Independent Variable } & \multicolumn{2}{|c|}{ Current smoker } & \multicolumn{2}{|c|}{ Non-smoker } & \multicolumn{2}{|c|}{ Total } & \multirow{2}{*}{ OR } & \multirow{2}{*}{$\mathbf{p}^{*}$} \\
\hline & $\mathbf{n}$ & $(\%)$ & $\mathbf{n}$ & $(\%)$ & $\mathbf{n}$ & $(\%)$ & & \\
\hline \multicolumn{9}{|c|}{ Exposure to cigarette commercials } \\
\hline Low $<49$ & 61 & 43 & 81 & 57 & 142 & 100 & \multirow{2}{*}{1.55} & \multirow{2}{*}{0.037} \\
\hline High $\geq 49$ & 139 & 53.9 & 119 & 46.1 & 258 & 100 & & \\
\hline \multicolumn{9}{|c|}{ Knowledge on smoking hazard } \\
\hline Poor $<17$ & 119 & 76.8 & 36 & 23.2 & 155 & 100 & \multirow{2}{*}{0.15} & \multirow{2}{*}{$<0.001$} \\
\hline Good $\geq 17$ & 81 & 33.1 & 164 & 66.9 & 245 & 100 & & \\
\hline \multicolumn{9}{|c|}{ Social capital of peer group } \\
\hline Weak $<29$ & 123 & 57.5 & 91 & 42.5 & 214 & 100 & \multirow{2}{*}{0.52} & \multirow{2}{*}{0.001} \\
\hline Strong $\geq 29$ & 77 & 41.4 & 109 & 58.6 & 186 & 100 & & \\
\hline \multicolumn{9}{|l|}{ Intention to smoke } \\
\hline Strong $<31$ & 150 & 78.9 & 40 & 21.1 & 190 & 100 & \multirow{2}{*}{0.08} & \multirow{2}{*}{$<0.001$} \\
\hline Weak $\geq 31$ & 50 & 23.8 & 160 & 76.2 & 210 & 100 & & \\
\hline \multicolumn{9}{|c|}{ Subjective norm toward smoking } \\
\hline Acceptable $<19$ & 165 & 76 & 52 & 24 & 217 & 100 & \multirow{2}{*}{0.07} & \multirow{2}{*}{$<0.001$} \\
\hline Unacceptable $\geq 19$ & 35 & 19.1 & 148 & 80.9 & 183 & 100 & & \\
\hline \multicolumn{9}{|c|}{ Attitude toward smoking } \\
\hline Positive $<51$ & 136 & 71.2 & 55 & 28.8 & 191 & 100 & \multirow{2}{*}{0.18} & \multirow{2}{*}{$<0.001$} \\
\hline Negative $\geq 51$ & 64 & 30.6 & 145 & 69.4 & 209 & 100 & & \\
\hline
\end{tabular}




\begin{tabular}{|c|c|c|c|c|c|c|c|c|}
\hline \multicolumn{9}{|l|}{ PBC not to smoke } \\
\hline Weak $<30$ & 150 & 76.1 & 47 & 23.9 & 197 & 100 & \multirow{2}{*}{0.10} & \multirow{2}{*}{$<0.001$} \\
\hline Strong $\geq 30$ & 50 & 24.6 & 153 & 75.4 & 203 & 100 & & \\
\hline \multicolumn{9}{|l|}{ Parental income } \\
\hline$<\mathrm{Rp} 1,400,000$ per month & 104 & 51 & 100 & 49 & 204 & 100 & \multirow{2}{*}{0.92} & \multirow{2}{*}{0.689} \\
\hline$\geq \operatorname{Rp} 1,400,000$ per month & 96 & 49 & 100 & 51 & 196 & 100 & & \\
\hline \multicolumn{9}{|l|}{ Access to cigarette } \\
\hline Difficult $<8$ & 96 & 51.6 & 90 & 48.4 & 186 & 100 & \multirow{2}{*}{0.88} & \multirow{2}{*}{0.548} \\
\hline Easy $\geq 8$ & 104 & 48.6 & 110 & 51.4 & 214 & 100 & & \\
\hline \multicolumn{9}{|l|}{ Smoking-free area } \\
\hline No & 17 & 54.8 & 14 & 45.2 & 31 & 100 & \multirow{2}{*}{0.81} & \multirow{2}{*}{0.575} \\
\hline Yes & 183 & 49.6 & 186 & 50.4 & 369 & 100 & & \\
\hline
\end{tabular}

$\mathrm{p}^{*}=\mathrm{p}$ value from Chi square test.

Table 2 showed sample characteristics by smoking status among youth. As expected, this bivariate analysis indicated that the risk of smoking increased with high exposure to cigarette commercials, and it was statistically significant $(\mathrm{p}<0.05)$. The bivariate analysis also indicated that the risk of smoking decreased with high knowledge of smoking hazard, high social capital, weak intention to smoke, unfavorable attitude toward smoking, unacceptable subjective norm toward smoking, and strong perceived behavior control not to smoke, and they were statistically significant $(\mathrm{p}<0.05)$. The differences in the prevalence of smokers were not statistically significant $(\mathrm{p} \geq 0.05)$ by parental income status, existence of smoking free are, and access to cigarettes.

\subsection{Path Analysis}

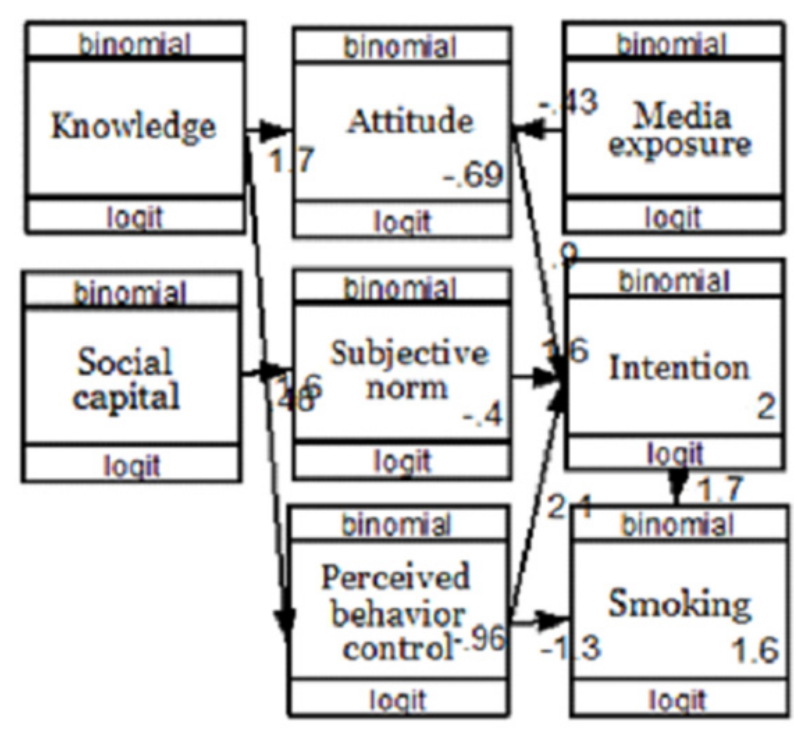

Figure 1. Path diagram on the determinants of tobacco smoking among youth 
Table 3. The results of path analysis on the determinants of tobacco smoking among youth

\begin{tabular}{|c|c|c|c|c|c|c|}
\hline \multirow[b]{2}{*}{ Dependent variable } & & \multirow[b]{2}{*}{ Independent variable } & \multirow{2}{*}{$\begin{array}{c}\text { Path } \\
\text { coefficient (b) }\end{array}$} & \multicolumn{2}{|c|}{$95 \% \mathrm{CI}$} & \multirow[b]{2}{*}{$\mathbf{p}$} \\
\hline & & & & $\begin{array}{c}\text { Lower } \\
\text { limit }\end{array}$ & $\begin{array}{l}\text { Upper } \\
\text { limit }\end{array}$ & \\
\hline \multicolumn{7}{|l|}{ Direct effect } \\
\hline Smoking & $\leftarrow$ & Intention to smoke (strong) & 1.74 & 1.19 & 2.30 & $<0.001$ \\
\hline Smoking & $\leftarrow$ & $\begin{array}{l}\text { Perceived behavior control (not to } \\
\text { smoke) }\end{array}$ & -1.32 & -1.87 & -0.77 & $<0.001$ \\
\hline \multicolumn{7}{|l|}{ Indirect effect } \\
\hline $\begin{array}{l}\text { Intention to smoke } \\
\text { (strong) }\end{array}$ & $\leftarrow$ & Attitude (positive toward smoking) & 0.90 & 0.29 & 1.51 & 0.004 \\
\hline $\begin{array}{l}\text { Intention to smoke } \\
\text { (strong) }\end{array}$ & $\leftarrow$ & $\begin{array}{l}\text { Subjective norm (smoking } \\
\text { acceptable) }\end{array}$ & 1.59 & 0.99 & 2.19 & $<0.001$ \\
\hline $\begin{array}{l}\text { Intention to smoke } \\
\text { (strong) }\end{array}$ & $\leftarrow$ & $\begin{array}{l}\text { Perceived behavior control (not to } \\
\text { smoke) }\end{array}$ & -2.07 & -2.68 & -1.45 & $<0.001$ \\
\hline $\begin{array}{l}\text { Attitude (positive toward } \\
\text { smoking) }\end{array}$ & $\leftarrow$ & $\begin{array}{l}\text { Knowledge about tobacco smoking } \\
\text { (poor) }\end{array}$ & 1.72 & 1.28 & 2.17 & $<0.001$ \\
\hline $\begin{array}{l}\text { Attitude (positive toward } \\
\text { smoking) }\end{array}$ & $\leftarrow$ & $\begin{array}{l}\text { Media exposure (e.g. cigarette } \\
\text { smoking commercials) }\end{array}$ & 0.43 & -0.02 & 0.88 & 0.063 \\
\hline $\begin{array}{l}\text { Perceived behavior } \\
\text { control (not to smoke) }\end{array}$ & $\leftarrow$ & $\begin{array}{l}\text { Knowledge about tobacco smoking } \\
\text { (poor) }\end{array}$ & 1.59 & 1.15 & 2.03 & $<0.001$ \\
\hline $\begin{array}{l}\text { Subjective norm (smoking } \\
\text { acceptable) }\end{array}$ & $\leftarrow$ & $\begin{array}{l}\text { Weak social capital (trust, norm of } \\
\text { reciprocity, social network) }\end{array}$ & 0.48 & 0.09 & 0.88 & 0.017 \\
\hline
\end{tabular}

$\mathrm{N}$ observation $=400$;

Log likelihood $=-1130.63$.

Table 3 showed the results of the final path model analysis, which retains the statistically significant relationships of variables under study. As customary, the path analysis table is divided into two panels, consisting of direct effects on the upper panel and indirect effects on the lower panel. On the direct effect, there was a positive and statistically significant relationship between intention to smoke and smoking behavior initiation. Specifically, on average youths with strong intention to smoke had logodd of smoking as much as 1.74 points higher than those with weak intention $(\mathrm{b}=1.74 ; 95 \% \mathrm{CI}=1.19$ to $2.30 ; \mathrm{p}<0.001)$.

On the direct effect, Table 3 also showed negative and statistically significant relationship between perceived behavior control not to smoke and smoking behavior initiation. Specifically, on average youths with strong perceived behavior control not to smoke had logodd of smoking as much as 1.32 points lower than those with weak perceived behavior control $(b=-1.32 ; 95 \% \mathrm{CI}=-1.87$ to $-0.77 ; \mathrm{p}<0.001)$.

On the indirect effect, Table 3 showed that intention to smoke had positive and statistically significant relationships with both attitude and subjective norm toward smoking. Specifically, on average youths with favorable attitude toward smoking had logodd of intention to smoke as much as 0.90 points higher than those with unfavorable attitude toward smoking $(b=0.90 ; 95 \% C I=0.29$ to $1.51 ; p=0.004)$. Similarly, on average youths with subjective norm that smoking is acceptable had logodd of intention to smoke as much as 1.59 points higher than those with subjective norm that smoking is unacceptable $(b=1.59 ; 95 \% \mathrm{CI}=0.99$ to $2.19 ; \mathrm{p}<0.001)$.

On the indirect effect, Table 3 also showed that intention to smoke had negative and statistically significant relationship with perceived behavior control not to smoke. Specifically, on average youths with strong perceived behavior control not to smoke had logodd of intention to smoke as much as 2.07 points lower than those with weak perceived behavior control not to smoke $(b=-2.07 ; 95 \% \mathrm{CI}=-2.68$ to $-1.45 ; \mathrm{p}<0.001)$.

On the indirect effect, Table 3 also showed that unfavorable attitude toward smoking had positive and statistically significant relationship with knowledge on smoking hazard. Specifically, on average youths with good knowledge on smoking hazard had logodd of unfavorable attitude toward smoking as much as 1.72 points higher than those 
with poor knowledge on smoking hazard $(b=1.72 ; 95 \% \mathrm{CI}=1.28$ to $2.17 ; \mathrm{p}<0.001)$.

On the indirect effect, Table 3 also showed that unfavorable attitude toward smoking had negative and statistically significant relationship with exposure to cigarette commercials. Specifically, on average youths with high exposure to cigarette commercials had logodd of unfavorable attitude toward smoking as much as 0.43 points lower than those with low exposure to cigarette commercials $(b=-0.43 ; 95 \% \mathrm{CI}=-0.88$ to $0.02 ; \mathrm{p}=0.063)$.

On the indirect effect, Table 3 also showed that perceived behavior control not to smoke had positive and statistically significant relationship with knowledge on smoking hazard. Specifically, on average youths with high knowledge on smoking hazard had logodd of perceived behavior control not to smoke as much as 1.59 points higher than those with low knowledge on smoking hazard $(b=1.59 ; 95 \% \mathrm{CI}=1.15$ to $2.03 ; \mathrm{p}<0.001)$.

On the indirect effect, subjective norm that smoking is unacceptable had positive and statistically significant relationship with social capital of peer group. Specifically, on average youths with high social capital of peer group had logodd of subjective norm that smoking is unacceptable as much as 0.48 points higher than those with low social capital of peer group $(b=0.48 ; 95 \% \mathrm{CI}=0.09$ to $0.88 ; \mathrm{p}=0.017)$.

\section{Discussion}

Identifying factors that influence individuals' smoking behavior remains a huge public health concern. To our knowledge, this is the first study that utilized a theory-based approach to understand cigarette smoking behavior among adolescents using path analysis technique. Young adulthood is a critical period in the development of smoking behavior (Hammond, 2005). The current study aimed to test the hypotheses using Theory of Planned Behavior (TPB) that the stronger intention to perform smoking behavior, the more likely the person is to perform smoking behavior. Likewise, the more positive a person's attitude, the stronger subjective norms, and the weaker perceived behavior control (PBC) not to smoke, the more likely the person is to perform smoking behavior.

\subsection{Smoking Behavior and Intention}

The path analysis of the present study provides empirical evidence that supports Theory of Planned Behavior (TPB). Consistent with TPB, intention was shown to be a direct predictor of smoking initiation. This finding is consistent with earlier study among waterpipe smokers in Saudi Arabia using a multiple logistic regression, which reported positive and statistically significant relationship between smoking and intention to smoke $(\mathrm{OR}=1.76$; $95 \% \mathrm{CI}=1.41$ to $2.21 ; \mathrm{p}<0.001$ ) (Alanazi et al., 2017). The current study was also consistent with the TPB's predictions in Topa and Moriano (2010) using a meta-analytic structural equation modeling approach (MASEM), which reported that smoking behavior was related to smoking intentions (weighted mean $\mathrm{r}=0.30$ ).

\subsection{Smoking Behavior and Attitude}

The present study showed an indirect relationship between unfavorable smoking attitude and smoking behavior through intention to smoke. Participants with unfavorable attitude toward smoking were more likely to smoke than those with favorable attitude. The direct relationship between smoking attitude and smoking behavior was negligible and statistically non-significant and so was not included in the path model. The current study is also consistent with Lin et al. (2010), which reported that subjects with a higher attitude score about smoking had relatively lower risk for cigarette smoking when compared to those with a lower attitude score, even after adjusting for potential confounders $(\mathrm{OR}=0.93 ; 95 \% \mathrm{CI}=0.91-0.94)$.

Grigaliūnaitè and Pilelienè (2017) elaborated further on the potential role of picture in modifying attitude toward smoking. Their study reported that smokers who saw unfavorable smoking-related pictures had more unfavorable attitude towards smoking when compared with those who saw favorable smoking-related pictures. The same situation is with the group of non-smokers: those non-smokers who saw unfavorable smoking-related pictures had a more unfavorable attitude towards smoking when compared with those who saw favorable smoking-related pictures.

\subsection{Smoking Behavior and Perceived Behavior Control}

According to the TPB, the behavior is a result of the intention to do the behavior and the PBC of the behavior. Finding from the current study supports the hypotheses that strong PBC not to smoke negatively predicts smoking behavior initiation among youth. According to TPB, the effect of PBC on the behavior can be direct or indirect. The direct negative relationship between PBC not to smoke and smoking behavior in the current study was statistically significant. Youth with strong PBC not to smoke were less likely to perform smoking. This finding is consistent with Alanazi et al. (2017), which reported that PBC (i.e. participants' confidence that they were able to perform cigarette smoking behavior) was positively related to smoking behavior ( $\mathrm{OR}=2.27 ; 95 \% \mathrm{CI}=1.51$ to 3.43; $\mathrm{p}<0.001)$. Another study by Smith et al. (2007) reported that PBC was associated with intention to smoke 
among high school adolescents.

\subsection{Smoking Behavior and Knowledge}

Path analysis in the current study supports the hypothesis that poor knowledge about smoking and health is associated with an increased tendency for adolescents to start smoking, by two different indirect pathways. The first pathway refers to the effect of knowledge on smoking behavior via increasing unfavorable attitude toward smoking and stronger intention to smoke. The second pathway refers to the effect of knowledge on smoking behavior via weaker perceived behavior control of not smoking. This finding explains better than other studies such as a study among young adults in China, which conclude that knowledge and attitude toward smoking do not necessarily translate into health behavioral outcomes such as smoking. The study by Xu et al. (2015) employed multiple regression analysis, which estimated only direct effects of knowledge and attitude on smoking behavior. It did not treat attitude, perceived behavior control, and intention, as mediating variables between knowledge and smoking behavior as it was in the current study.

The current study found positive association between poor knowledge and unfavorable attitude toward smoking, positive association between unfavorable attitude and stronger intention to smoke, as well as strong intention to smoke and smoking behavior. Likewise, the current study found positive association between poor knowledge and weaker perceived behavior control not to smoke, as well as weak perceived behavior control and smoking behavior In contrast with the study reported by Xu et al. (2015), we did not find statistically significant direct association between knowledge and smoking behavior. The direct relationship between smoking attitude and smoking behavior was negligible and statistically non-significant and so was not included in the path model.

The current study is consistent with Lin et al. (2010), which reported that subjects with greater knowledge about smoking had a lower risk of smoking $(\mathrm{OR}=0.88 ; 95 \% \mathrm{CI}=0.86-0.91)$. But this characteristic diminished after being adjusted for potential confounders.

\subsection{Smoking Behavior and Subjective Norm}

The current study showed the indirect relationship between subjective norm toward smoking and smoking behavior through intention to smoke. Adolescents with favorable subjective norm were more likely to have stronger intention to smoke than those with unfavorable subjective norm. Subsequently, adolescents with strong intention to smoke were more likely to engage in smoking behavior than those with weak intention to smoke. The current study did not find direct significant relationship between subjective norm and smoking behavior. Accordingly, the path diagram dropped this path as it diminished the fitness of the model. This finding is consistent with Alanazi et al. (2017), which reported no direct effect of subjective norm on the cigarette use behavior, yet reported that subjective norm had a statistically significant indirect effect on intentions through attitude and perceived behavioral control.

\subsection{Smoking Behavior and Media Exposure}

Path analysis of the current study showed how smoking related messages on social media influenced high school students' smoking. High school students with high exposure to pro-smoking messages on electronic mass media, social media, and advertisement, were more likely to engage in smoking than those with low exposure to pro-smoking messages, via unfavorable attitude toward smoking and strong intention to smoke. This finding is consistent with a study in the USA by Yoo et al. (2016), which reported that reception of pro-smoking messages not only directly affected smoking but also had indirect effects on smoking through (1) perceived peer expression of pro-smoking messages and (2) perceived peer smoking norms.

\subsection{Smoking Behavior and Social Capital}

The current study found a positive indirect relationship between weak group social capital and smoking behavior among adolescents, through unfavorable subjective norm toward smoking and strong intention to smoke. Adolescents with weak group social capital were more likely to have unfavorable subjective norm toward smoking, to have strong intention to smoke, and eventually to engage in smoking behavior than those with strong group social capital. This finding is consistent with Lindstrom and Giordano (2016), which reported that active social participation was positively associated with smoking cessation $(\mathrm{OR}=1.39 ; 95 \% \mathrm{CI}=1.07$ to 1.82$)$. Likewise, a systematic review reported the importance of social environment to help affect smoking cessation (Kristina et al., 2018).

As postulated by Kreider et al. (2016), active social participation in social capital may be an instrumental part of individuals' social networks, through which societal 'norms' regarding smoking behavior can be disseminated and reinforced. Group (participatory) interventions have already been shown to increase success rates of smoking 
cessation.

\subsection{Limitation}

The cross-sectional survey design limits our ability to explore the causal relationship between the variables, because all observations were made at the same time.

\section{Conclusion}

Theory of Planned Behavior (TPB) can be used to explain psychological and social factors affecting smoking behavior among adolescents. The TPB constructs including attitude toward smoking, subjective norm toward smoking, and perceived behavior control not to smoke, have impact on intention to smoke, and eventually on smoking behavior. Social capital affects smoking behavior via subjective norm and intention. Knowledge about smoking and health affects smoking behavior via attitude toward smoking and perceived behavior control not to smoke. Mass media exposure affects smoking behavior via attitude and intention. The relationships involving multiple variables including mediating variable can be analyzed using path analysis. These findings can be used to design health promotion program to prevent and reduce smoking behavior among adolescents.

\section{Authorship}

SujonoRiyadi raised the original research questions, developed questionnaire, collected data, and sought ethical clearance letter. BhismaMurti designed the study, determined sampling approach, revised questionnaire, analyzed data, and interpreted the results, discussed the findings, and wrote up the manuscript. Muhammad Akhyar discussed and reviewed the data analysis approach. Suminah discussed the results.

\section{Competing Interests Statement}

The authors declare that there are no competing or potential conflicts of interest.

\section{References}

Alanazi, N. H., Lee, J. W., Santos, H. D., Job, J. S., \& Bahjri, K. (2017). The use of planned behavior theory in predicting cigarette smoking among Waterpipe smokers. Tobacco Induced Diseases, 15, 29. https://doi.org/10.1186/s12971-017-0133-z

AlKandari, N. Y. (2016). Motivation for smoking in male college students in Kuwait. International Journal of Health Promotion and Education, 54(5), 217-228. https://doi.org/10.1080/14635240.2016.1157510

Amaya, R. M. R. (2018). Factors Associated with Smoking and Alcohol Consumption among Street Vendors in the Metropolitan Area of Bucaramanga, Colombia. Global Journal of Health Science, 10(9), 103-111. https://doi.org/10.5539/gjhs.v10n9p103

Gaioso, V. P., Villarruel, A. M., Wilson, L. A., Azuero, A., Childs, G. D., \& Davies, S. L. (2015). A Path Analysis of Latino Parental, Teenager and Cultural Variables in Teenagers' Sexual Attitudes, Norms, Self-Efficacy, and Sexual Intentions. Rev Lat Am Enfermagem, 23(3), 500-11. https://doi.org/10.1590/0104-1169.0398.2581.

Government of Canada. (2008). Terminology. Retrieved November, 2018, from https://www.canada.ca/en/healthcanada/services/healthconcerns/tobacco/research/tobacco-use-statistics/terminology.html

Grigaliūnaitè, V., \& Pilelienè, L. (2017). Attitude toward smoking: the effect of negative smoking-related pictures. OeconomiaCopernicana, 8(2), 317-328. https://doi.org/10.24136/oc.v8i2.20

Hammond, D. (2005). Smoking behavior among young adults: beyond youth prevention. Tobacco Control. 14,181-185. https://doi.org/10.1136/tc.2004.009621

Hanson, M. J. S. (2018). Attitudes and perceptions about cigarette smoking among nonsmoking high school students.J Am Assoc Nurse Pract, 30(2), 60-63. https://doi.org/ $\neg 10.1097-/ J X X .0000000000000005$

Huong, N. T., Kien, N. T., Giang, K. B., Minh, H. V., Hai, P. T., Huyen, D. T., ... Nga, P. T. (2016). Knowledge and Attitude Towards Tobacco Smoking among 13-15 Year-Old School Children in Viet Nam - Findings from GYTS 2014. Asian Pac J Cancer Prev., 17(S1), 37-42. http://dx.doi.org/10.7314/APJCP.2016.17.S1.37

Ilany, A., \& Akçay, E. (2016). Personality and Social Networks: A Generative Model Approach. Integr Comp Biol., 56(6), 1197-1205. https://doi.org/10.1093/icb/icw068

Khaja, A. H., Zwiad, A. A., Tarakji, B., Gazal, G., Albaba, F., KalajiI, N., \& Petro, W. (2016).The dependence on smokeless tobacco in the South Asian Communities in East London. Global Journal of Health Science, 8(1), 194-198. https://doi.org/10.5539/gjhs.v8n1p194

Kreider, C. M., Bendixen, R. M., Young, M. E., Prudencio, S. M., McCarty, C., \& Mann, W. C. (2016). Social networks and participation with others for youth with learning, attention, and autism spectrum disorders. Can J OccupTher, 83(1), 14-26. https://doi.org/10.1177/0008417415583107 
Kristina, S. A., Trung, V. Q., Permitasari, N. P. A. L., Dwinta, E., \& Rahman, F. (2018). Individual, social and psychological characteristics of smoking cessation behaviors: A systematic review. Global Journal of Health Science, 10(10), 55-64. https://doi.org/10.5539/gjhs.v10n10p55

LaMorte, W. W. (2018). The theory of planned behavior.Boston University School of Public Health.Retrieved September, 2018, from http://sphweb.bumc.bu.edu/otlt/MPH-Modules/SB/BehavioralChangeTheories/BehavioralChangeTheories3.html

Lin, Y. S., Wu, D. M., Lai, H. R., Shi, Z. P., \& Chu, N. F. (2010). Influence of knowledge and attitudes on smoking habits among young military conscripts in Taiwan. $J$ Chin Med Assoc., 73(8), 411-418. https://doi.org/10.1016/S1726-4901(10)70089-7

Lindstorm, M. (2008). Social capital, social class, and tobacco smoking. Pharmacoeconomics Outcomes Res., 8(1), 81-89. https://doi.org/10.1586/14737167.8.1.81

Lindstrom, M., \&Giordano, G. N. (2016). Changes in social capital and cigarette smoking behavior over time: a population-based panel study of temporal relationships. Nicotine \& Tobacco Research, 18(11), 2106-2114. https://doi.org/10.1093/ntr/ntw120

Lundborg, P. (2005). Social capital and substance use among Swedish adolescents - an explorative study. Soc. Sci. Med., 61(5), 1151-1158. https://doi.org/10.1016/j.-socscimed.2004.12.031

Macy, J. T., Chassin, L., \& Presson, C. C. (2012). Smoking behaviors and attitudes during adolescence prospectively predict support for tobacco control policies in adulthood. Nicotine Tob Res., 14(7), 871-879. https://doi.org/10.1093/ntr/ntr301

Moore, S., \& Kawachi, I. (2017). Twenty years of social capital and health research: a glossary. $J$ Epidemiol Community Health, 71(5), 513-517. https://doi.org/10.1136/jech-2016-208313

Moore, S., Daniel, M., Gauvin, L., \& Dube, L. (2009). Not all social capital is good capital. Health \& Place, 15, 1071-1077. https://doi.org/10.1016/j.healthplace.2009.05.005

Shimazaki, T., Bao, H., Deli, G., Uechi, H., Lee, Y. H., Miura, K., \&Takenaka, K. (2018).Psychological reactance in smoking cessation among inner Mongolian students. International Journal of Health Promotion and Education, 56(6), 269-279. https://doi.org/10.1080-/14635240.2018.1522265

Smith, B. N., Bean, M. K., Mitchell, K. S., Speizer, I. S., \& Fries, E. A. (2007). Psychosocial factors associated with non-smoking adolescents' intentions to smoke. Health Education Research, 22(2), 238-247. https://doi.org/10.1093/her/cyl072

StataCorp LLC. (2018). Structural equation modeling (SEM). StataCorp LLC. Retrieved June, 2018, from https://www.stata.com/features/structural-equation-modeling

Tobacco Atlas. (2018). Indonesia Country Facts. Retrieved September, 2018, from https://s27854.pcdn.co/wp-content/uploads/-pdf/indonesia-country-facts.pdf

Topa, G., \& Moriano, J. A. (2010). Theory of planned behavior and smoking: meta-analysis and SEM model. Subst Abuse Rehabil, 1, 23-33. https://doi.org/10.2147/SAR.S15168

Ullman, J. B. (1996). Structural equation modeling. In: B. G. Tabachnick, \& L. S. Fidell (Eds.), Using multivariate statistics (3rd ed., pp. 709-819). New York, NY: Harper Collins College Publishers.

Wolf, E. J., Harrington, K. M., Clark, S. L., \& Miller, M. W. (2013). Sample Size Requirements for Structural Equation Models: An Evaluation of Power, Bias, and Solution Propriety. Educ Psychol Meas., 76(6), 913-934. https://doi.org/10.1177/0013164413495237

Xu, X., Liu, L., Sharma, M., \& Zhao, Y. (2015). Smoking-related knowledge, attitudes, behaviors, smoking cessation idea and education level among young adult male smokers in Chongqing, China. Int $J$ Environ Res Public Health, 12(2), 2135-2149. https://doi.org/-10.3390/ijerph120202135

Yoo, W., Yang, J., \& Cho, E. (2016). How social media influence college students' smoking attitudes and intentions. Comput Human Behav., 64, 173-182. https://doi.org/10.1016/-j.chb.2016.06.061

\section{Copyrights}

Copyright for this article is retained by the author(s), with first publication rights granted to the journal.

This is an open-access article distributed under the terms and conditions of the Creative Commons Attribution license (http://creativecommons.org/licenses/by/4.0/). 